\title{
Variation in Antioxidant Activity and Flavonoid Aglycones in Eggplant (Solanum melongena L.) Germplasm
}

\author{
Xiang-Min Piao ${ }^{1,2}$, Jong-Wook Chung ${ }^{2}$, Gi-An Lee ${ }^{2}$, Jung-Ro Lee, Gyu-Taek Cho ${ }^{2}$, Ho-Sun Lee ${ }^{2}$, Kyung-Ho Ma $^{2}$, \\ Jing Guo ${ }^{1}$, Hong Sig Kim³, Sok-Young Lee ${ }^{2}$ * \\ ${ }^{1}$ Institute of Special Wild Economic Animal and Plants, Chinese Academy of Agriculture Sciences, Changchun, Jilin 130112, \\ People's Republic of China \\ ${ }^{2}$ National Agrobiodiversity Center, NAAS, RDA, Jeonju 560-500, Republic of Korea \\ ${ }^{3}$ Department of Crop Science, Chungbuk National University, Cheongju 361-763, Republic of Korea
}

\begin{abstract}
Eggplant (Solanum melongena L.) is an excellent source of vitamins A and C and of flavonoid compounds, which are important antioxidant components believed to reduce the risk of various diseases. We investigated the antioxidant activity and flavonoid content in eggplant leaves and fruits to identify genetic resources with high antioxidant capacity for use in food or as feed additives, and also determined the influence of days to flowering, leaf blade colors, and latitudes of origin on the antioxidant activity and flavonoid content in eggplant leaves. The accessions originating from $45^{\circ} \mathrm{N}$ showed the highest flavonoid contents $(\mathrm{AVG} .=15.4$ $\mu \mathrm{g} \mathrm{mg}^{-1}$ ) followed by accessions from $30^{\circ} \sim 45^{\circ} \mathrm{N}\left(\mathrm{AVG} .=13.0 \mu \mathrm{g} \mathrm{mg}^{-1}\right), 15^{\circ} \sim 30^{\circ} \mathrm{N}\left(\mathrm{AVG} .=11.0 \mu \mathrm{g} \mathrm{mg}{ }^{-1}\right)$, and $^{\circ} \sim 15^{\circ} \mathrm{N}(\mathrm{AVG} .=$ $9.5 \mathrm{mg} \mathrm{mg}^{-1}$ ). The same pattern was also found in 2,2'-azino-bis(3-ethylbenzothiazoline-6-sulfonic acid) (ABTS) and 1,1-diphenyl-2picryl-hydrazil (DPPH) antioxidant activities. High ABTS and DPPH activity and flavonoid content were found in the early-flowering accessions. All flavonoids of the greenish violet leaves were significantly higher than those of green leaves. The flavonoid concentration in eggplant leaves was 10 to 20 fold greater, at an average of $15.6 \mu \mathrm{g} \mathrm{mg}^{-1}$, than that of the fruit $\left(\mathrm{AVG}\right.$. $\left.=0.9 \mu \mathrm{g} \mathrm{mg}{ }^{-1}\right)$. Taken together, eggplant leaves represent a potential source of natural antioxidants due to their high flavonoid content.
\end{abstract}

Keywords Antioxidant activity, Eggplant, Flavonoid aglycone, Germplasm

\section{INTRODUCTION}

Eggplant (Solanum melongena L.) is a vegetable crop from the nightshade family (Solanaceae) that originated in warm regions of India and China (Lawande and Chavan 1998). Eggplant is an excellent source of vitamin A and C and of flavonoid compounds, which are important antioxidant components that may reduce the risk of disease (George 1985; Konys 1993). Flavonoid compounds and antioxidant activity occur in most parts of the eggplant, including the calyx, leaf, fruit, and stem (Saddiqe et al. 2011). Methods using the stable 2,2'-azino-bis(3-ethylbenzothiazoline-6sulfonic acid) (ABTS) or 1,1-diphenyl-2-picryl-hydrazil (DPPH) radicals are widely used to evaluate the free radical-scavenging ability of antioxidants (Nabavi et al.
2009). Both methods have excellent reproducibility under certain assay conditions, but they show significant differences in their responses to antioxidants (Arnao 2000). The range of flavonoids occurring in plant materials is usually large, and every plant has an original and unique flavonoid profile, which makes quantification difficult. For this reason, flavonoid aglycones are frequently used to determine total flavonoid content, which can reduce the variability (Webb and Harborne 1991). These aglycones can be quantified using ultraviolet (UV) spectrophotometric methods, as described previously (Miean and Mohamed 2001), and several high-performance liquid chromatography procedures have been used to quantify flavonoid aglycones. Quercetin, myricetin, kaempferol, and isorhamnetin are the four most widespread flavonoid aglycones (Olszewska 2007).

Received October 8, 2014; Revised October 20, 2014; Accepted October 22, 2014; Published December 31, 2014

*Corresponding author Sok-Young Lee, 1sy007@korea.kr, Tel: +82-63-238-4810, Fax: +82-63-238-4859 
Although previous studies have revealed that ethanol (EtOH) extracts of eggplant leaves have higher antioxidant activity and total flavonol content than do their fruits (Jung et al. 2011), most eggplant leaves are discarded as waste. To the best of our knowledge, no published studies have determined the influences of agronomic traits and latitudes of origin of specific accessions on the antioxidant activity and flavonoids in eggplant leaves. In this study, we investigated the antioxidant activity and flavonoid content in eggplant leaves and fruits to identify genetic resources with a high antioxidant capacity for use in food or as feed additives, and also determined how days to flowering, leaf blade colors, and latitudes of origin influenced the antioxidant activity and flavonoid content in eggplant leaves.

\section{MATERIALS AND METHODS}

\section{Materials}

In total, 102 eggplant accessions collected from 15 countries (Table 1, Fig. 1) were classified into four clusters by their latitudes of origin, $45^{\circ} \mathrm{N}(n=9), 30^{\circ} \sim 45^{\circ} \mathrm{N}(n=$ $31), 15^{\circ} \sim 30^{\circ} \mathrm{N}(n=22)$, and $0^{\circ} \sim 15^{\circ} \mathrm{N}(n=40)$, and then divided into three groups based on their days to flowering (80 days, $n=26$; $80 \sim 90$ days, $n=44$, and 90 days, $n=32$ ). All accessions were sown on April 4 in the plug plate and planted on June 5, 2013 in an open field at National Agrobiodiversity Center in Suwon, Korea. The experiment was laid out in completely randomized design (CRD) with three replications. A plot was consisted of six plants of each accession in one row. Plant spacing was $100 \mathrm{~cm}$ between rows and $30 \mathrm{~cm}$ between plants.

Table 1. $\mathrm{NAC}^{\mathrm{z})}$ registration numbers and origins of 102 eggplant accessions investigated in this study.

\begin{tabular}{|c|c|c|c|c|c|c|c|c|c|}
\hline $\begin{array}{c}\text { NAC } \\
\text { registration } \\
\text { number }\end{array}$ & $\begin{array}{l}\text { Country } \\
\text { of origin }\end{array}$ & $\begin{array}{c}\text { NAC } \\
\text { registration } \\
\text { number }\end{array}$ & $\begin{array}{l}\text { Country } \\
\text { of origin }\end{array}$ & $\begin{array}{c}\text { NAC } \\
\text { registration } \\
\text { number }\end{array}$ & $\begin{array}{l}\text { Country } \\
\text { of origin }\end{array}$ & $\begin{array}{c}\text { NAC } \\
\text { registration } \\
\text { number }\end{array}$ & $\begin{array}{l}\text { Country } \\
\text { of origin }\end{array}$ & $\begin{array}{c}\text { NAC } \\
\text { registration } \\
\text { number }\end{array}$ & $\begin{array}{l}\text { Country } \\
\text { of origin }\end{array}$ \\
\hline 1. IT219140 & CAN & 22. IT189726 & JPN & 43. IT136561 & NPL & 64. IT201082 & PHL & 85. IT218791 & RUS \\
\hline 2. IT170475 & $\mathrm{CHN}$ & 23. IT189727 & JPN & 44. IT136562 & NPL & 65. IT201084 & PHL & 86. IT218790 & RUS \\
\hline 3. IT208418 & $\mathrm{CHN}$ & 24. IT189728 & JPN & 45. IT136564 & NPL & 66. IT201087 & PHL & 87. IT224506 & RUS \\
\hline 4. IT213107 & $\mathrm{CHN}$ & 25. IT189763 & JPN & 46. IT136566 & NPL & 67. IT201088 & PHL & 88. IT224477 & RUS \\
\hline 5. IT218742 & $\mathrm{CHN}$ & 26. IT189764 & JPN & 47. IT189771 & NPL & 68. IT201089 & PHL & 89. IT218616 & THA \\
\hline 6. IT218770 & $\mathrm{CHN}$ & 27. IT189769 & JPN & 48. IT200247 & NPL & 69. IT201090 & PHL & 90. IT218694 & THA \\
\hline 7. IT218771 & $\mathrm{CHN}$ & 28. IT189770 & JPN & 49. IT200249 & PHL & 70. IT201091 & PHL & 91. IT218697 & THA \\
\hline 8. IT180718 & EGY & 29. IT102771 & KOR & 50. IT201053 & PHL & 71. IT201092 & PHL & 92. IT218699 & THA \\
\hline 9. IT180719 & EGY & 30. IT103969 & KOR & 51. IT201057 & PHL & 72. IT201096 & PHL & 93. IT218700 & THA \\
\hline 10. IT189729 & IDN & 31. IT104244 & KOR & 52. IT201059 & PHL & 73. IT201100 & PHL & 94. IT218772 & THA \\
\hline 11. IT136568 & IND & 32. IT136571 & KOR & 53. IT201060 & PHL & 74. IT201101 & PHL & 95. IT218774 & THA \\
\hline 12. IT136569 & IND & 33. IT220040 & KOR & 54. IT201063 & PHL & 75. IT201102 & PHL & 96. IT218775 & THA \\
\hline 13. IT136570 & IND & 34. IT203193 & MDA & 55. IT201071 & PHL & 76. IT201103 & PHL & 97. IT218776 & THA \\
\hline 14. IT208416 & IND & 35. IT183769 & MYS & 56. IT201072 & PHL & 77. IT201112 & PHL & 98. IT203186 & UKR \\
\hline 15. IT208417 & IND & 36. IT110943 & NPL & 57. IT201073 & PHL & 78. IT201113 & PHL & 99. IT203178 & UZB \\
\hline 16. IT218701 & IND & 37. IT136552 & NPL & 58. IT201074 & PHL & 79. IT201116 & PHL & 100. IT203179 & UZB \\
\hline 17. IT 189720 & JPN & 38. IT136553 & NPL & 59. IT201077 & PHL & 80. IT201117 & PHL & 101. IT218709 & UZB \\
\hline 18. IT189721 & JPN & 39. IT136554 & NPL & 60. IT201078 & PHL & 81. IT201118 & PHL & 102. IT218722 & UZB \\
\hline 19. IT189722 & JPN & 40. IT136556 & NPL & 61. IT201079 & PHL & 82. IT201124 & PHL & & \\
\hline 20. IT189724 & JPN & 41. IT136557 & NPL & 62. IT201080 & PHL & 83. IT203188 & RUS & & \\
\hline 21. IT189725 & JPN & 42. IT136558 & NPL & 63. IT201081 & PHL & 84. IT203189 & RUS & & \\
\hline
\end{tabular}

\footnotetext{
z) National Agrobiodiversity Center
} 


\section{Chemicals}

DPPH, 1-ascorbic acid, ABTS, 6-hydroxy-2,5,7,8-tetramethylchroman-2-carboxylic acid (Trolox), quercetin, apigenin, kaempferol, and isorhamnetin were purchased from Sigma-Aldrich (St. Louis, MO, USA). All other reagents were of analytical grade.

\section{Sample preparation}

Crude extracts were produced using $7 \mathrm{~g}$ of oven-dried eggplant leaves and fruits from each accession using an ASE-200 extractor (Dionex, Sunnyvale, CA, USA). Extractions were performed in $40 \mathrm{ml}$ of $75 \% \mathrm{EtOH}$ under nitrogen gas at $1500 \mathrm{psi}$ and $70^{\circ} \mathrm{C}$. Extracted samples were dried using an HT-4X vacuum concentrator (Genevac, Stone Ridge, NY, USA).

\section{DPPH assay}

The free radical-scavenging activity of the extracts was assessed by the DPPH method proposed by Lee and Lee (2004), with slight modifications. A DPPH solution (150 $\mu \mathrm{l} ; 150 \mu \mathrm{M}$ in anhydrous EtOH) was added to $100 \mu \mathrm{l}$ of sample solution. The mixture was shaken vigorously and left to stand at $25^{\circ} \mathrm{C}$ in the dark for $30 \mathrm{~min}$. Absorbance at $517 \mathrm{~nm}$ was then measured with a ELISA (Bio-Teck, Epoch, US). DPPH free radical scavenging activity was calculated using the following equation:

DPPH scavenging effect $(\%)=[1-(\mathrm{A} 0-\mathrm{A} 1) /(\mathrm{A} 2-\mathrm{A} 3)] \times 100$ where $\mathrm{A} 0, \mathrm{~A} 1, \mathrm{~A} 2$, and $\mathrm{A} 3$ are the absorbance of the sample, the sample blank, the control, and the control blank, respectively. The radical scavenging effect is expressed as micrograms l-ascorbic acid equivalent antioxidant capacity (ASC) per $1 \mathrm{mg}$ dried extract ( $\mu \mathrm{g}$ ASC $\mathrm{mg}^{-1}$ dry weight).

\section{ABTS assay}

ABTS radical scavenging activity was estimated using the method in Re et al. (1999) with some modifications. The ABTS radical cation was generated by adding $7 \mathrm{mM}$ ABTS to $2.45 \mathrm{mM}$ potassium persulfate, followed by overnight incubation of the mixture in the dark at room temperature. The ABTS radical cation solution was diluted with methanol $(\mathrm{MeOH})$ to obtain an absorbance of $0.7 \pm$ 0.02 at $735 \mathrm{~nm}$. A diluted ABTS radical cation solution $(190 \mu \mathrm{l})$ was added to $10 \mu \mathrm{l}$ of sample solution. After $6 \mathrm{~min}$, absorbance at $735 \mathrm{~nm}$ was determined using ELISA. The capability to scavenge the ABTS radical was calculated using the following equation:

ABTS scavenging effect $(\%)=[1-(\mathrm{A} 0-\mathrm{A} 1) /(\mathrm{A} 2-\mathrm{A} 3)] \times 100$

where $\mathrm{A} 0, \mathrm{~A} 1, \mathrm{~A} 2$, and $\mathrm{A} 3$ are defined as above. The free radical scavenging effect of each sample was reported as the Trolox equivalent antioxidant activity obtained by comparing the changes in absorbance at $735 \mathrm{~nm}$ in reaction mixtures containing a sample eggplant extract or a Trolox equivalent.

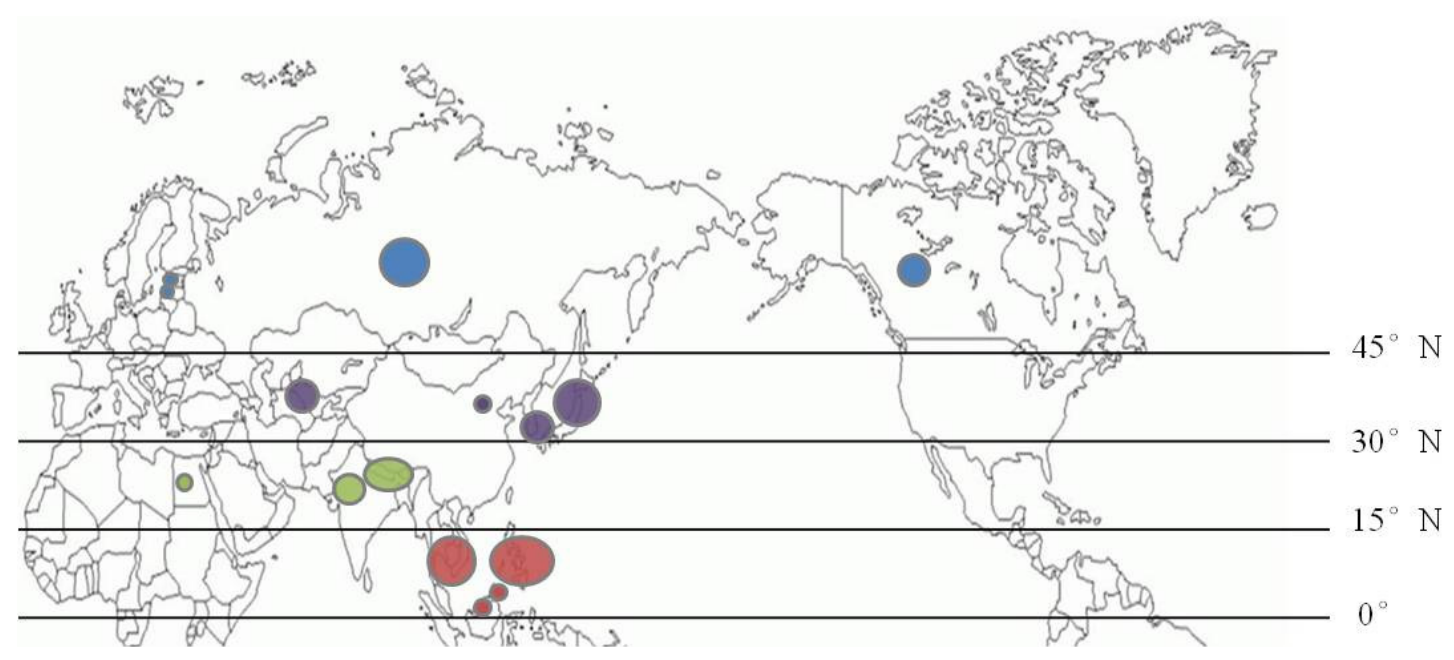

Fig. 1. Distribution of 102 eggplant accessions by their countries of collection. 


\section{Flavonoid aglycones assay}

Flavonoid aglycone contents of the eggplant fruits and leaves were investigated using high-performance liquid chromatography (Thermo Scientific, Waltham, MA, USA) with a hypersil ODS column $(125 \times 4 \mathrm{~mm}, 5-\mu \mathrm{m}$ particle, HP). Flavonoid aglycone contents were estimated using the method in Olszewska (2007) with some modifications. Fifty milligrams of eggplant leaf and fruit extracts was heated at $90^{\circ} \mathrm{C}$ for $2 \mathrm{~h}$ with $10 \mathrm{ml}$ of $1 \mathrm{~N}$ hydrochloric acid, followed by shaking for $2 \mathrm{~h}$ with $10 \mathrm{ml}$ of $\mathrm{MeOH}$. The hydrolysate was diluted with $\mathrm{MeOH}$ to $25 \mathrm{ml}$ using a volumetric flask and filtered through a PTFE syringe filter (13 mm, 0.45- $\mu \mathrm{m}$ pore; Whatman, Maidstone, Kent, UK). Detection was performed at $370 \mathrm{~nm}$.

\section{Statistical analyses}

Duncan's multiple range tests (DMRTs) were carried out to test for significant differences among eggplant germplasms using SAS (version 9.1; SAS Institute, Inc., Cary, NC, USA). Principal components analysis (PCA) was applied to identify the antioxidant activity and flavonoids, which were the main source of the variability, and to explain the genetic diversity in eggplant germplasm.

\section{RESULTS}

Four typical flavonoid aglycones were observed in all eggplant leaf samples, which were identified as quercetin, apigenin, kaempferol, and isorhamnetin by comparing them with the retention times of standard compounds (Fig. 2). Flavonoid aglycone concentrations in eggplant green leaves, greenish violet leaves, and fruits are compared in Fig. 3. All flavonoids of the greenish violet leaves were significantly higher than those of green leaves. The flavonoid concentration in eggplant leaves was 10 to 20 fold higher (with an average of $15.6 \mu \mathrm{g} \mathrm{mg}^{-1}$ ) than that of the fruit (AVG. $=0.9 \mu \mathrm{g} \mathrm{mg}^{-1}$ ), and apigenin and isorhamnetin were not detected in eggplant fruit, which suggests that eggplant leaves represent a potential source of natural antioxidants due to their very high flavonoid concentrations. ABTS (73.9 $\mu \mathrm{g}$ Trolox $\left.\mathrm{mg}^{-1}\right)$ and DPPH (53.1 $\mu \mathrm{g}$ ASC $\mathrm{mg}^{-1}$ ) activity, and quercetin $\left(3.0 \mu \mathrm{g} \mathrm{mg}^{-1}\right)$, apigenin $\left(1.6 \mu \mathrm{g} \mathrm{mg}^{-1}\right)$, kaempferol $\left(8.8 \mu \mathrm{g} \mathrm{mg}^{-1}\right)$, and total flavonoid aglycone concentrations $\left(12.9 \mu \mathrm{g} \mathrm{mg}^{-1}\right)$ in the early-flowering accessions (days to flowering $<80$ days) were found to be significantly higher than those in other accessions (Table $2)$. The accessions originating from $45^{\circ} \mathrm{N}$ showed the highest flavonoid concentrations (AVG. $=15.4 \mu \mathrm{g} \mathrm{mg}^{-1}$ ), followed by accessions that originated from $30^{\circ} \sim 45^{\circ} \mathrm{N}$
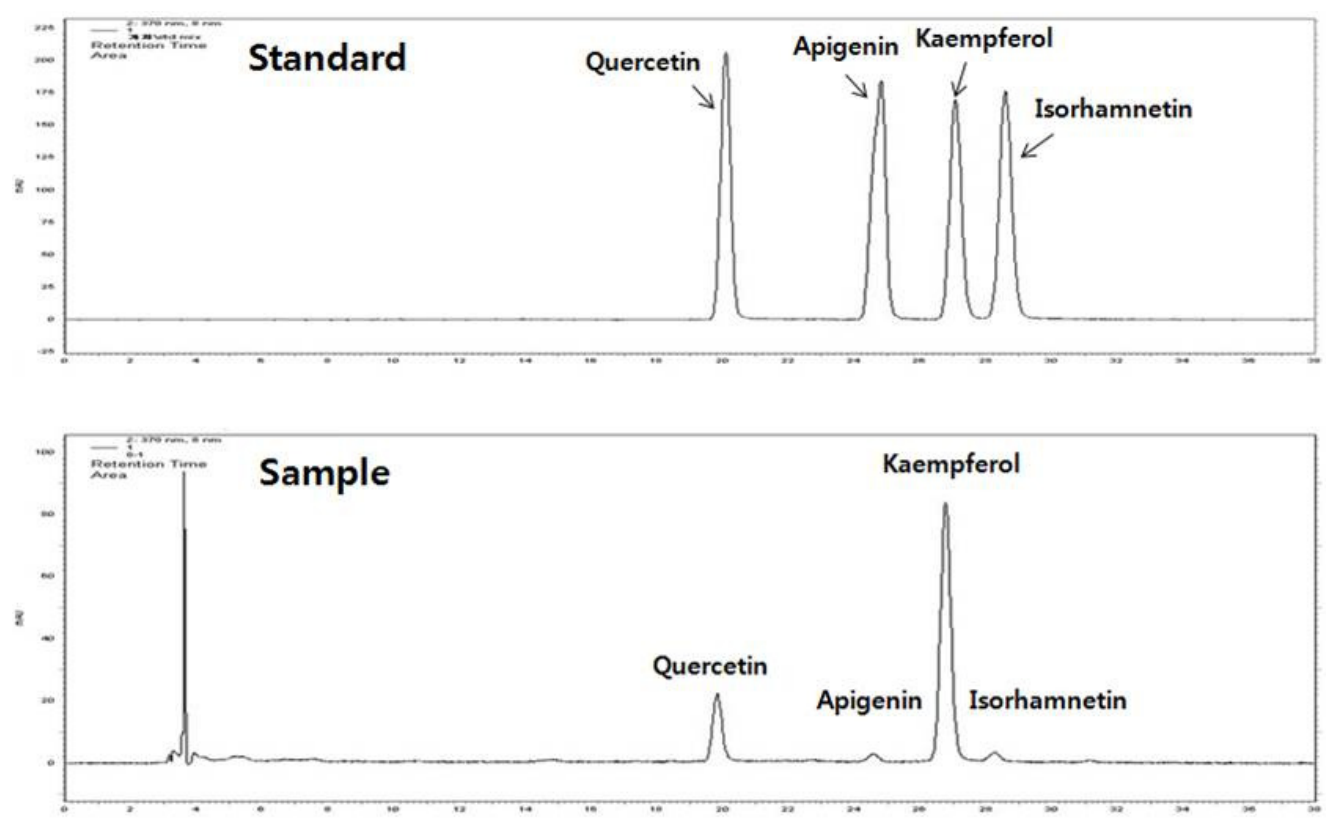

Fig. 2. Standard and sample chromatograms of flavonoid aglycones in eggplant. 
$\left(\right.$ AVG. $\left.=13.0 \mu \mathrm{g} \mathrm{mg}^{-1}\right), 15^{\circ} \sim 30^{\circ} \mathrm{N}\left(\right.$ AVG. $\left.=11.0 \mu \mathrm{g} \mathrm{mg}^{-1}\right)$, and $0^{\circ} \sim 15^{\circ} \mathrm{N}\left(\right.$ AVG. $\left.=9.5 \mu \mathrm{g} \mathrm{m}^{-1}\right)$. The same patterns were also found in ABTS and DPPH antioxidant activities (Table 3). The PCA using a correlation matrix and Pearson correlation coefficients indicated that the first three principal components (PCs) explained $79 \%$ of the total variance among accessions; PC1, PC2, and PC3 explained 40\%, $25 \%$, and $14 \%$ of the variance, respectively. Thus, based on PC1, ABTS and DPPH antioxidant activity and all flavonoid aglycones displayed relatively high contributions to the

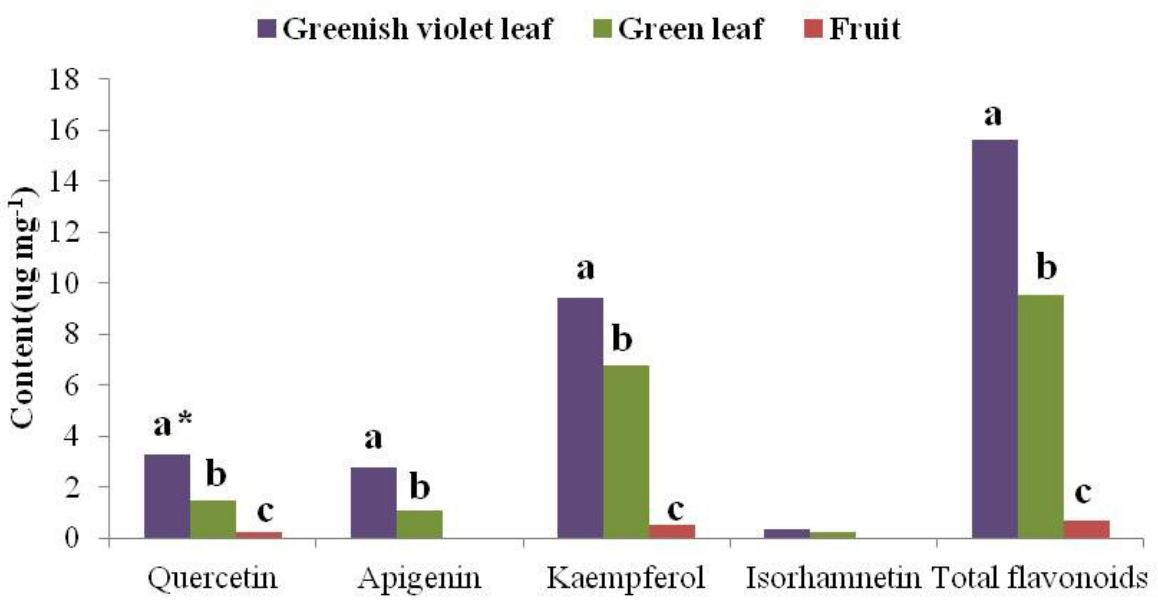

*The same letter in each column indicates no significant difference by Duncan's multiple range test, $p<0.05$

Fig. 3. Flavonoid contents classified by leaves and fruits in 102 eggplant germplasm.

Table 2. Flavonoid contents and antioxidant activity classified by days to flowering in germplasm of leaves of 102 eggplant accessions.

\begin{tabular}{|c|c|c|c|c|c|c|c|}
\hline \multirow{2}{*}{$\begin{array}{l}\text { Days to } \\
\text { flowering }\end{array}$} & \multicolumn{5}{|c|}{ Flavonoid aglycnes (ug $\mathrm{mg}^{-1}$ ) } & \multicolumn{2}{|c|}{ Antioxidant activity } \\
\hline & Quercetin & Apigenin & Kaempferol & Isorhamnetin & $\begin{array}{c}\text { Total } \\
\text { flavonoid }\end{array}$ & $\mathrm{DPPH}^{\mathrm{y})}$ & $\operatorname{ABTS}^{\mathrm{x})}$ \\
\hline$<\sim 80(n=26)$ & $3.0 \pm 1.1 \mathrm{a}^{\mathrm{z})}$ & $1.6 \pm 0.5 \mathrm{a}$ & $8.8 \pm 2.5 \mathrm{a}$ & $0.3 \pm 0.1$ & $12.9 \pm 3.7 \mathrm{a}$ & $53.1 \pm 12.1 \mathrm{a}$ & $73.9 \pm 11.2 \mathrm{a}$ \\
\hline $81 \sim 90(n=44)$ & $2.0 \pm 0.6 \mathrm{~b}$ & $1.3 \pm 0.5 \mathrm{~b}$ & $6.5 \pm 1.7 b$ & $0.4 \pm 0.1$ & $9.5 \pm 2.8 b$ & $50.9 \pm 12.2 \mathrm{ab}$ & $62.9 \pm 10.1 b$ \\
\hline$>91 \quad(n=32)$ & $1.7 \pm 0.5 b$ & $1.2 \pm 0.4 \mathrm{~b}$ & $5.5 \pm 1.1 b$ & $0.3 \pm 0.1$ & $8.5 \pm 2.0 b$ & $46.3 \pm 13.3 b$ & $56.2 \pm 10.8 b$ \\
\hline
\end{tabular}

Table 3. Flavonoid contents and antioxidant activity classified by origin latitude in germplasm of leaves of 102 eggplant accessions.

\begin{tabular}{|c|c|c|c|c|c|c|c|}
\hline \multirow[b]{2}{*}{ Latitude } & \multicolumn{5}{|c|}{ Flavonoid aglycones (ug $\mathrm{mg}^{-1}$ ) } & \multicolumn{2}{|c|}{ Antioxidant Activity } \\
\hline & Quercetin & Apigenin & Kaempferol & Isorhamnetin & $\begin{array}{c}\text { Total } \\
\text { flavonoid }\end{array}$ & $\mathrm{DPPH}^{\mathrm{y})}$ & $\operatorname{ABTS}^{\mathrm{x})}$ \\
\hline $45^{\circ} \mathrm{N}(\mathrm{n}=9)$ & $2.5 \pm 0.5$ & $1.9 \pm 0.4 a^{z)}$ & $10.9 \pm 1.6 \mathrm{a}$ & $0.3 \pm 0.2$ & $15.4 \pm 2.7 \mathrm{a}$ & $56.5 \pm 16.3 \mathrm{a}$ & $75.6 \pm 10.5 \mathrm{a}$ \\
\hline $30 \sim 45^{\circ} \mathrm{N}(\mathrm{n}=31)$ & $2.5 \pm 0.8$ & $1.4 \pm 0.5 \mathrm{ab}$ & $8.5 \pm 2.0 \mathrm{~b}$ & $0.4 \pm 0.1$ & $13.0 \pm 3.7 \mathrm{ab}$ & $52.2 \pm 15.1 b$ & $67.1 \pm 12.3 \mathrm{ab}$ \\
\hline $15 \sim 30^{\circ} \mathrm{N}(\mathrm{n}=22)$ & $1.9 \pm 0.6$ & $1.4 \pm 0.6 \mathrm{ab}$ & $6.8 \pm 1.5 \mathrm{c}$ & $0.3 \pm 0.1$ & $11.0 \pm 3.3 \mathrm{bc}$ & $51.8 \pm 16.1 \mathrm{~b}$ & $66.5 \pm 17.3 \mathrm{ab}$ \\
\hline $0 \sim 15^{\circ} \mathrm{N}(\mathrm{n}=40)$ & $1.8 \pm 0.6$ & $1.1 \pm 0.5 \mathrm{~b}$ & $6.3 \pm 1.9 \mathrm{c}$ & $0.3 \pm 0.1$ & $9.5 \pm 2.8 \mathrm{c}$ & $51.4 \pm 15.0 \mathrm{~b}$ & $60.6 \pm 12.4 \mathrm{~b}$ \\
\hline
\end{tabular}


total variance, whereas $\mathrm{PC} 2$ was characterized mainly by ABTS and DPPH antioxidant activity (Table 4). The biplot of the first two PCs, including loading of the ABTS and DPPH antioxidant activity and flavonoid aglycone content, is given in Fig. 4. This figure indicates that the $45^{\circ} \mathrm{N}$ group including Canada, Russia, Ukraine, and Moldova resources had high ABTS and DPPH antioxidant activity, whereas high flavonoid level resources were clustered in the $30^{\circ} \sim$ $45^{\circ} \mathrm{N}$ group. The first two components accounted for $65 \%$ of the total variance in 102 eggplant accessions. IT213107 from China was recommended as a potential source of natural antioxidants due to its high ABTS $(83.6 \mu \mathrm{g}$ Trolox $\left.\mathrm{mg}^{-1}\right)$ and DPPH (73.6 $\left.\mu \mathrm{g} \mathrm{ASC} \mathrm{mg}^{-1}\right)$ antioxidant activity and high total flavonoid content $\left(21.0 \mu \mathrm{g} \mathrm{mg}^{-1}\right)$ among accessions.

\section{DISCUSSION}

The range of flavonoids occurring in plant materials is generally reported to be large, and every plant has an original and unique flavonoid profile, which makes quantification difficult. For this reason, flavonoid aglycones are frequently used to determine the total flavonoid content, which can

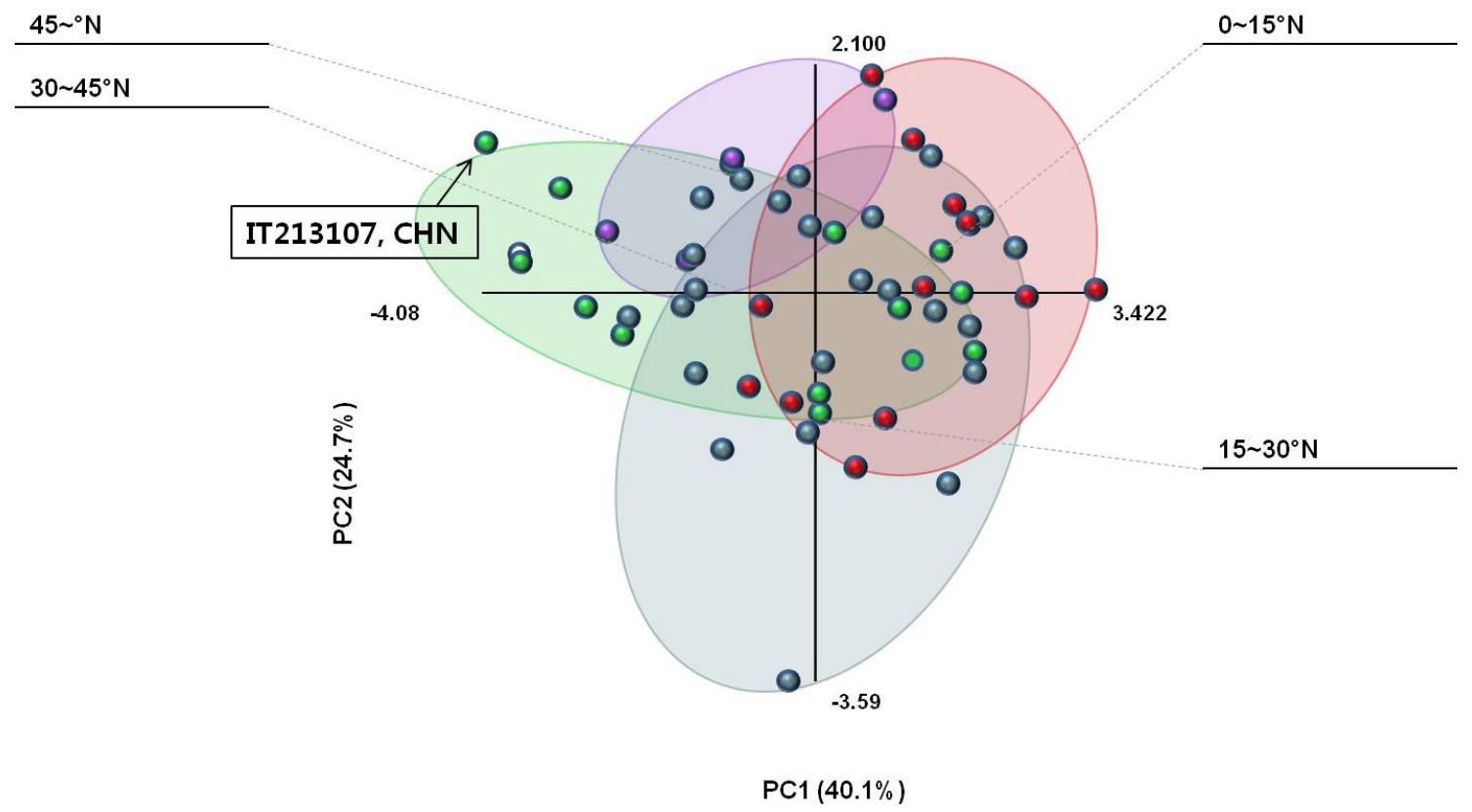

Fig. 4. Plot of the first and second principal components classified by the latitude of origin for 102 eggplant leaves.

Table 4. Principal components analysis of germplasm of 102 eggplant accessions, with the eigenvalues and eigenvectors of antioxidant activity and flavonoids.

\begin{tabular}{cccc}
\hline \hline Variables & Comp 1 & Comp 2 & Comp 3 \\
\hline Quercetin & -0.46 & -0.37 & 0.27 \\
Apigenin & -0.46 & -0.27 & 0.18 \\
Kaempferol & -0.32 & -0.08 & -0.94 \\
Isorhamnetin & -0.46 & -0.26 & 0.07 \\
DPPH & -0.36 & 0.61 & 0.06 \\
ABTS & -0.38 & 0.59 & 0.10 \\
Contribution & $40 \%$ & $25 \%$ & $14 \%$ \\
Cumulative contribution & $40 \%$ & $65 \%$ & $79 \%$ \\
Eigenvalue & 2.06 & 1.27 & 0.72 \\
\hline
\end{tabular}


lower the variability (Webb and Harborne 1991). So in this study, eggplant flavonoids were investigated by calculating the flavonoid aglycone concentrations of quercetin, apigenin, kaempferol, and isorhamnetin. Quercetin has been reported to be a major flavonoid in most plant extracts (Miean and Mohamed 2001). However, in this study, eggplant leaves were found to mainly accumulate kaempferol, which accounted for more than $70 \%$ of the total flavonoids. This finding will provide valuable information for developing resources having high kaempferol concentrations. A previous study indicated that the temperature of the place of collection showed a negative correlation with antioxidant activities and flavonoids (Åkerstöm et al. 2010). Similar results were found in our study; accessions originating from $45^{\circ} \sim 60^{\circ} \mathrm{N}$ displayed the highest flavonoid concentrations, followed by accessions originating, in order, from $30^{\circ} \sim 45^{\circ} \mathrm{N}, 1$ $5^{\circ} \sim 30^{\circ} \mathrm{N}$, and $0^{\circ} \sim 15^{\circ} \mathrm{N}$. This result concurred with the PCA reported earlier in this paper, which showed that the $0 \sim 15^{\circ} \mathrm{N}$ group and $45^{\circ} \sim 60^{\circ} \mathrm{N}$ group were different (Fig. 4). These results can be explained by the other finding, namely that either low latitude or high temperature at the geographical origin may lead to low antioxidant activity (Ghasemi et al. 2011; Piao et al. 2013). Previous studies reported that EtOH extracts of eggplant leaves had higher DPPH radical scavenging activity and total flavonol content than did their fruits (Jung et al. 2011; Madukwe et al. 2013). Similarly, in this study, eggplant leaves had significantly higher flavonoid concentrations than their fruit had (Fig. 3). From these results, it can be concluded that eggplant leaves represent a potential source of natural antioxidants due to their very high flavonoid concentrations. The biplot (Fig. 4) indicates that the $45^{\circ} \mathrm{N}$ group had high ABTS and DPPH antioxidant activity, whereas high flavonoid-level resources were clustered in the $30^{\circ} \sim 45^{\circ} \mathrm{N}$ group. Thus, this plot can be used to categorize genetic entities in making eggplant breeding decisions.

\section{ACKNOWLEDGMENTS}

This work was supported by the Rural Development Administration (RDA), Republic of Korea (Project No. PJ008625), and postdoctoral program.

\section{REFERENCES}

Akerstöm A, Jaakola L, Bang U, Jäderlund A. 2010. Effects of latitude-related factors and geographical origin on anthocyanidin concentrations in fruits of Vaccinium myrtillus L. Agric. Food Chem. 58: 11939-11945.

Arnao MB. 2000. Some methodological problems in the determination of antioxidant activity using chromogen radicals: a practical case. Trends Food Sci. Technol. 11: 419-421.

George R. 1985. Vegetable seed production. London and New York, pp. 223-229.

Ghasemi K, Ghasemi Y, Ehteshamnia A, Nabavi SM, Nabavi SF, Ebrahimzadeh MA, Pourmorad F. 2011. Influence of environmental factors on antioxidant activity, phenol and flavonoids contents of walnut (Juglans regia L.) green husks. J. Med. Plant Res. 5: 1128-1133.

Jung EJ, Bae MS, Jo EK, Jo YH, Lee SC. 2011. Antioxidant activity of different parts of eggplant. J. Med. Plant Res. 5: 4610-4615.

Konys E. 1993. Warzywa psiankowate. Gapiński M., (red.), Warzywa mało znane i zapomniane. PWRiL, Poznań, pp. 78-82.

Lawande KE, Chavan JK. 1998. Eggplant (Brinjal), handbook of vegetable science and technology. Production, composition, storage and processing. New York, pp. 225-244.

Lee DJ, Lee JY. 2004. Antioxidant activity by DPPH assay. Korean J. Crop Sci. 49: 187-194.

Madukue EU, Ani PN, Ezeonu C. 2013. Comparative Analysis of Antioxidant Vitamins in Extracts of Three Vegetables among the Commonly Consumed in South-Eastern Nigeria. Global Res. Anal. 2: 94-95.

Miean KH, Mohamed S. 2001. Flavonoid (myricetin, quercetin, kaempferol, luteolin, and apigenin) content of edible tropical plants. J. Agric. Food Chem. 49: 3106-3112.

Nabavi SM, Ebrahimzadeh MA, Nabavi SF, Fazelian M, Eslami B. 2009. In vitro antioxidant and free radical scavenging activity of Diospyros lotus and Pyrus boissieriana growing in Iran. Pharmacog. Mag. 5: 122-126.

Olszewska M. 2007. Quantitative HPLC analysis of flavonoids and chlorogenic acid in the leaves and inflorescences of Prunus aerotina EHRH. Acta Chromatogr. 19: 253-269.

Piao XM, Jang EK, Chung JW, Lee GA, Lee HS, Sung JS, Jeon YA, Lee JR, Kim YG, Lee SY. 2013. Variation in antioxidant activity and polyphenol content in tomato 
stems and leaves. Plant Breed. Biotechnol. 1: 366-373.

Re R, Pellegrini N, Proteggente A, Pannala A, Yang M, Rice-

Evans C. 1999. Antioxidant activity applying an improved ABTS radical cation decolorisation assay. Free Rad. Biol. Med. 26: 1231-1237.

Saddiqe Z, Naeem I, Mughal T, Taskeen A, Mubeen H. 2011.
Characterization of flavonoid aglycones in aerial parts of Hypericum oblongifolium L. Asian J. Chem. 23: 939-940. Webb ME, Harborne JB. 1991. Leaf flavonoid aglycone patterns and sectional classification in the genus Vicia (Leguminosae). Biochem. Syst. Ecol. 19: 81-86. 